\title{
The Verbal Component of Mathematical Problem Solving in Bilingual Contexts by Early Elementary Schoolers
}

\author{
Pilar Ester ${ }^{1, *(1)}$, Isabel Morales ${ }^{1}$, Álvaro Moraleda ${ }^{1} \mathbb{C}$ and Vicente Bermejo ${ }^{2}$ \\ 1 Faculty of Education, Camilo José Cela University, 28692 Madrid, Spain; imorales@ucjc.edu (I.M.); \\ amoraleda@ucjc.edu (Á.M.) \\ 2 Faculty of Psychology, Complutense University of Madrid, 28040 Madrid, Spain; bermejo@psi.ucm.es \\ * Correspondence: pester@ucjc.edu
}

Citation: Ester, P.; Morales, I.;

Moraleda, Á.; Bermejo, V. The Verbal

Component of Mathematical Problem

Solving in Bilingual Contexts by Early Elementary Schoolers. Mathematics

2021, 9, 564. https://doi.org/

$10.3390 /$ math 9050564

Academic Editors: Jarmila Novotná and Alena Hošpesová

Received: 31 January 2021

Accepted: 27 February 2021

Published: 6 March 2021

Publisher's Note: MDPI stays neutral with regard to jurisdictional claims in published maps and institutional affiliations.

Copyright: (c) 2021 by the authors. Licensee MDPI, Basel, Switzerland. This article is an open access article distributed under the terms and conditions of the Creative Commons Attribution (CC BY) license (https:/ / creativecommons.org/licenses/by/ $4.0 /)$.

\begin{abstract}
The main aim of the present study is to analyze the differences that may exist when students address the resolution of verbal problems in their mother tongue and in the language of instruction when these are different. We understand that knowing the type of verbal problems and their semantic structure can be helpful for students' contextual and mathematical understanding and will allow teachers to improve instruction during the first years of elementary education in bilingual schools specialized in the area of second language acquisition as well as in CLIL (Content and Language Integrated Learning). This study shows how children, as they are acquiring a greater command of the second language, show similar effectiveness to those students who work on mathematics in their mother tongue. This transversal study was conducted on 169 bilinguals studying in international schools. The sample was made up of 80 1st grade students (39 girls, mean age of 7.1 years and 41 boys, mean age of 7.3 years); and 89 2nd grade students ( 38 girls, mean age 8.2 years, and 51 boys, mean age 8.2 years). The exploratory analyses let us show how 1st grade students demonstrate lower effectiveness in solving problems when they do it in a second language, compared to 2nd grade students whose effectiveness is higher in carrying them out. It is also relevant that in first graders, the largest number of errors are found in the simplest tasks as students' effectiveness is less when they are taught in a second language, since it takes them longer to create effective resolution models. This fact will allow us to reconsider appropriate strategies and interventions when teaching mathematics in bilingual contexts.
\end{abstract}

Keywords: bilingual programs; mathematical thinking development; language of instruction; solve problems; CLIL

\section{Introduction}

During the last decades, we can observe that there are many studies that deal with the relationship between mathematics and language, and if we add to this combination other phenomena such as multilingualism, bilingualism and translanguaging, the number of studies is even larger. In this respect, the study conducted by the ICMI (International Commission on Mathematical Instruction) under the title "Mathematics education and language diversity" published in 2009 [1], highlights the importance of linguistic diversity in mathematics education.

For any educational system, it is quite challenging to know how to work in linguistic and culturally diverse contexts in order to improve the teaching-learning processes of mathematics. However, the real challenge arises when we want to find out how to use most effectively all the students' informal mathematical awareness that the students have obtained earlier and show when they come to school and, in many cases, to discover how to work with that knowledge when it does not coincide with the language of instruction used in the classrooms. 
The main aim of our study is to explain how students solve mathematical problems in the first years of compulsory elementary schooling. As such tasks are formed by a large linguistic and logical component, students often have difficulty in understanding them.

Some studies, as in the case of Van Rinsveld et al. [2], criticize immersion programs since, on many occasions, they assume that the contents learned are sufficiently independent of language to be transferred to the students' mental language. Our theoretical position is based on this premise and follows the idea that, depending on the content taught in a second language, the pedagogical strategies would be characterized by the idiosyncrasies of the subject itself. For this reason, we try to shed some light on how to cope with problem solving in bilingual educational contexts and to find out what semantic structures can make it more difficult to understand the problem, and if it differs when it is presented in the mother tongue and how any informal knowledge can be involved in this complex process. We start from the hypothesis that there may be significant differences in the resolution of problems associated with the influence of language when they are carried out in a second language. In this respect, we expect that the patterns in the second language could be similar to those that have already been investigated in the first language, implying the difficulty of addition and subtraction problems derived from its linguistic structure.

\section{State of the Art: Teaching Mathematics in Bilingual Contexts}

If we based our study on more classical criteria [3], we should say that bilingualism is limited to the use of two languages as if both of them were native languages. We believe, however, that this can leave aside many situations and contexts that could also be considered as bilingual. We see Planas's view [4] as more appropriate when considering the bilingual as a speaker who masters one language and is capable of constructing meanings in a second language.

According to Cummins [5] there are many studies conducted in situations of additive bilingualism that show many positive effects. As Cummins states, there is "...a critical threshold level of L1 and L2 ability that must be attained before the positive effects of bilingualism can be observed" [6], p. 341. Nevertheless, mastering both languages (L1 or first language or mother tongue, and L2 or second language) requires longer exposure time and the right contexts. According to De Houwer, "Both bilingual speaker's language input history and the sociolinguistic settings to which he or she has been accustomed are elements pertaining to the environmental conditions in which bilingual language use takes place" [7], p. 253. Following the author, we find that the researchers' interest is given to "... real-life" language use rather than artificial, laboratory-induced language behavior, implying that it is highly important to consider all these environmental and contextual conditions when setting up data collection sessions.

The development of linguistic skills takes place because of the speaker's language awareness itself and, above all, the characteristics of the speaker's socialization contexts [8]. It is a relevant fact to consider when learning mathematics, specifically acquiring those concepts in which communicating and interacting with others take a center stage to guarantee their understanding. The social element of interaction should be a priority in the learning of mathematics, whether it is a bilingual context or not, since through dialogical learning between peers, learning is equally or more enriching than any vertical teacher-student communication [9].

Therefore, the language role in the classroom, and specifically the role of the language of instruction used, allows us to further expand the concept exposed at the beginning, since from the perspective of its pedagogical role, language is considered as a vehicle in the development of the learning objectives, far ahead of its social and pedagogically weak role in the description of reality and its diversity $[4,10]$.

Barton [11] states that "we bring mathematics into existence by talking about it, and the way we talk about it changes the questions we can ask" (p. 227). In order to understand the cognitive effect that occurs in second language teaching, we can start, as explained in Figure 1, from the proficient command of both languages. We see that having a high 
linguistic level in both languages has positive effects, but what happens when we are at a lower level of language proficiency in bilingual contexts?

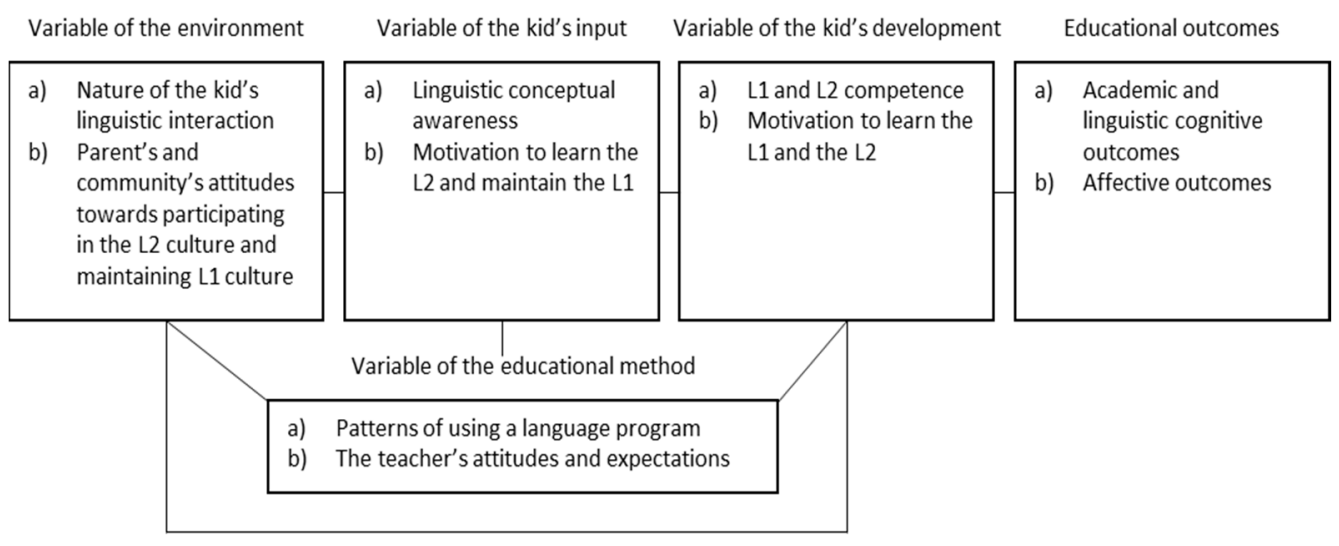

Figure 1. Interactive model of bilingual education Barton (2012).

Taking into account that in the first years of elementary education, linguistic skills are low in both L1 and L2, this may be one of the reasons for the low impact on a cognitive level. The hypothesis of the linguistic interdependence proposed by Cummins [12] claims that a child's L2 command depends partly on the level of proficiency achieved in the L1 or mother tongue, that is, it is necessary to have the CUP (common underlying proficiency) well developed either in the first language or the additional language, or in both languages. According to Cummins [13] it is due to the fact that for distant languages the transfer takes place mainly from personality and cognitive attributes, while for more related languages the linguistic elements are also transferred.

In multilingual contexts, children who are exposed to language input in two different languages tend to acquire the two syntactic structures when both of them are similar. However, when these structures are much more complex in one of the two languages, they will tend to acquire first the language whose syntax is easier [14].

The improvement of linguistic competences and the development of mathematical concepts, therefore, lead us to value the concept of translanguaging, which, unlike codeswitching and codemixing, is not simply a matter of speakers changing languages, but of constructing, and using complex and original interrelated discursive practices [15]. In the vast majority of the cases, these situations take place in contexts where English coexists with other languages or is used for professional or educational purposes, "because English tends to be one of the languages in the multilingual speaker's repertoire and one of the languages used in society" [16], p. 301.

Quite often, it has been emphasized that the language of instruction is a powerful vehicle for mathematical thinking since people who speak two or more languages tend to carry out activities associated with memory, such as counting in the language that mathematics has been learned. In anecdotal cases, we can find that both languages coexist and are mixed up in these types of tasks. According to previous studies it has been demonstrated how bilingual students perform calculations more quickly and efficiently in their first language compared to a second language [17,18], although performance is higher if the person shows a higher language command in any of the languages [19].

However, when it comes to with problem solving, the contrast is highly noticeable since people solve problems and cope with the situation more quickly and efficiently when these are presented in their dominant language [17,20,21]. On one hand, as Dehaene [22,23] proposes, in order to retrieve arithmetic data in a second language, these would come from a translation process or from a less systematic learning of facts in the second language. On the other hand, McCloskey [24] speaks about the transformation processes that can occur in problem solving. McCloskey's hypothesis is based on the fact that the numbers and arithmetic data are represented regardless of the language, but in order to access these 
representations, the person must transform the problem into a representation to calculate an answer, which, in turn, must be transformed back into the language spoken. These two processes to decode and encode will be involved in the speed and performance to find the response.

It is also necessary for our study to consider the phenomenon of translanguaging [25], a term coined by Cen Williams in Wales to refer to bilingualism where speakers alternate between language modes especially in teaching and learning [26-28]). It has been demonstrated that this phenomenon is a natural process occurring in school contexts where two or more languages are used by students and teachers [15].

As García [26] puts it, it occurs when bilingual students and teachers engage in different types of practices including home language in order to communicate appropriate content knowledge and also work on academic language activities. Language practices are dynamic and fluid, and bilinguals select language resources from a repertoire to fit their communicative tasks.

For our study we have also based on the study of Li Wei [28], who deals with translanguaging as a phenomenon occurring when going from and to different linguistic structures and systems in speaking, listening, reading, signing and remembering. According to Canagarajah [27], multilingual speakers feed from all languages in their repertoire when they need to communicate in educational contexts, something that will lead us to base our analysis on students' understanding and using an additional language when resolving verbal problems.

\section{Problem Solving}

The resolution of problems is one of the major difficulties that students encounter when they are learning mathematics, but it is the basis for such a learning field [29-36]. Some of the reasons for low performance is that the first thing students have to do is to read a text and are faced with a linguistic barrier. This implies, on one hand, that the student must carry out a reading comprehension exercise to later establish a representation that will allow him/her to start up a planning so as to apply a strategy for the resolution of the problem. On the other hand, it implies that the student must have certain conceptual knowledge that must be applied and that, as we will see later, on some occasions, is more or less complex than others, depending on the characteristics of the problem itself. Those mathematical activities that are more complex require more advanced language skills [37].

We have found many studies that have been conducted in order to establish problem solving models [38-41] and although they all may be supplying several different appraisals, what they all do is to give special importance to the representation that must be carried out prior to problem planning.

As Orrantia [42] explains, during the process of text interpretation, we can distinguish two aspects. The former has to do with the information that the base text offers, where the superficial and semantic aspects are visible and permit the establishment of the relationships between the numbers, actions, sets and the relationships between those sets. The second aspect refers to the model of the problem that informs the conceptual basis that the student has about both his informal knowledge and problem-solving abilities. At the same time, the student must create a model of the problem situation, that is, the mental representation that will later allow him to move onto the next decision-making stage. This can be seen in those constructivist intervention processes in which the child creates and invents his own problem-solving strategies [43].

The importance of the representation created by the student once he understands the text becomes especially important when mathematics is instructed in a language different from the dominant language. In this respect, we would be highly interested to know if this process occurs in a similar way or as explained above, if it is necessary to introduce into this scheme two interrelated encoding and decoding processes that would entail bringing into play more complex cognitive processes. Luevano and Colins [44] demonstrated that through a culturally appropriate problem-solving instruction (CAPSI) intervention which 
incorporates diagrams, vocabulary acquisition and video modeling, problem solving will improve in the early school years.

\section{The Present Study}

The focus of this study lies in the analysis of a community of multilingual speakers, who have acquired two or more languages either simultaneously or sequentially. The first group have acquired two or more languages at the same time, implying that they are early simultaneous speakers of several languages. These students have been regularly exposed to two languages from before the age of two and have continued to be regularly addressed in those languages. The second group, making up most of the participants of the present study, have been mainly raised exposed to one language or mother tongue which is different from the main language used in the educational context of the community. In this latter case, they have not developed the same metalinguistic knowledge in a language different from their first language, thus potentially hindering the development of mathematical concepts in the second language used for mathematics instruction. It is important to note that the sample children at the time of observation were definitely in an additive bilingual situation, as it has also been conducted in some investigations [6] implying that they were progressing in both L1 and L2 rather than L2 gradually replacing L1, and their language command is developed at their age average.

We have focused only on problem solving tasks, the type of mathematical tasks and previous experiences that during the first years of compulsory elementary education are less frequent compared to other educational stages. In addition, it should be noted that the command of the first language is also in process, therefore, it is not completed yet. Nor is the second language developed. We found that students were at different levels of linguistic skill development. Students were presented the tests both in oral and in written format for which they only provided an oral answer.

\section{Materials and Methods}

The sample consisted of 169 students in bilingual contexts belonging to 1st and 2nd grades of elementary education from two international schools. The sample was made up of 80 1st grade students ( 39 girls, mean age of 7.1 years and $\mathrm{SD}=3.2$ months years and 41 boys, mean age of 7.3 years and $\mathrm{SD}=2.8$ moths); and 89 2nd grade students (38 girls, mean age 8.2 years and $\mathrm{SD}=2.3$ moths, and 51 boys, mean age 8.2 years $\mathrm{SD}=3.4$ moths). It is a convenience sample where the number of participants equals the number of students who are part of the international school in 1st and 2nd grades in which the study was conducted. In these multicultural and multilingual schools, there are students from many different nationalities, i.e., Brazil, USA, Portugal, England and Italy, among others. One of the main reasons to carry out the study in these international schools is that they have some common characteristics, for instance, that students have had the same time of exposure to the second language in the school, mostly with native teachers. The methodology implemented in these centers follows the IB (International Baccalaureate) program, therefore we can find very few differences, being only related to the teacher's personal classroom management characteristics. See Table 1 for grade and sex distribution.

Table 1. Sample distribution according to degree and sex.

\begin{tabular}{cccccc}
\hline & \multicolumn{2}{c}{ Female } & \multicolumn{2}{c}{ Male } & Total \\
\cline { 2 - 6 } & $\mathbf{n}$ & Average Age & $\mathbf{n}$ & Average Age & $\mathbf{N}$ \\
\hline 1st grade & 39 & 7.1 & 41 & 7.3 & 80 \\
\hline 2nd grade & 38 & 8.2 & 51 & 8.2 & 89 \\
\hline
\end{tabular}

Once we obtained the authorization to carry out the research, a presentation letter of the study was sent to the management teams of all the schools involved, who subsequently informed the families after its approval by the management team. Taking into 
account that the participants were minors, they were sent an informed consent letter that their parent/guardian had to sign. All the data were obtained anonymously and treated confidentially.

All participants had been exposed to the same linguistic immersion in the second language, and they all spoke Spanish and English at different levels of proficiency. In both international centers the linguistic immersion program developed is one of the educational priorities and is implemented throughout the school years, from kindergarten to the last years of secondary education, implying a great linguistic and cultural variety. All through the kindergarten courses, the immersion program is fully implemented in English. In one of the schools, all subjects in elementary education are taught in English except for the Spanish language, whereas in the other school both Spanish language and mathematics are taught in Spanish. In other words, the only difference between the two schools is the language of instruction used to teach mathematics, a situation that made us form two distinct groups according to whether or not their mother tongue coincides with the language of instruction.

The tests provided were the following:

- The Raven Colored Progressive Matrices test [45]. We used it to assess whether there were significant IQ differences among the participants.

- $\quad$ The second test used was the Perception of Differences Test [46], which was intended for evaluating the attentional processes in the participants.

- Finally, we administered individually to each participant 20 addition and subtraction word problems. In any case no more than twenty problems were provided per participant. The answer was recorded as correct when the student knew how to explain the answer. When the answers were given at random, these were considered invalid. The selection of problems was based on the TEDI-MATH scale test, but since they did not cover all types of problems for assessment, they were complemented with problems extracted from the research carried out by Bermejo et al. [47], being sequenced in an increasing order of difficulty following the classification established in Bermejo, Lago y Rodríguez [48] (see Table 2):

Table 2. Classification of problems.

\begin{tabular}{|c|c|c|c|}
\hline TYPE & ITEM & EXAMPLE & PART REQUESTED IN THE RESOLUTION \\
\hline Change 2 & 6 & $\begin{array}{l}\text { There are } 4 \text { fish in a pond and David throws } \\
\text { some more into the pond. If there are } 8 \text { fish } \\
\text { now, how many fish did David throw? }\end{array}$ & Change \\
\hline Change 3 & 1 & $\begin{array}{c}\text { Luis has got } 2 \text { marbles and gains } 2 \text { more } \\
\text { playing. How many marbles will he } \\
\text { finally have? }\end{array}$ & Result \\
\hline Change 3 & 3 & $\begin{array}{l}\text { Carolina has got } 3 \text { books and her father gives } \\
\text { her another } 5 \text {. How many books does she } \\
\text { finally have? }\end{array}$ & Result \\
\hline Change 4 & 10 & $\begin{array}{c}\text { Pedro has got several marbles and gains } 3 \text { in } \\
\text { the playground. If he has } 6 \text { marbles now, how } \\
\text { many did he have before going to the } \\
\text { playground? }\end{array}$ & Beginning \\
\hline Change 4 & 11 & $\begin{array}{l}\text { María had got several eggs, but } 2 \text { were broken. } \\
\text { If there are } 3 \text { eggs left now, how many did she } \\
\text { have before they were broken? }\end{array}$ & Beginning \\
\hline Change 5 & 7 & $\begin{array}{l}\text { There are } 7 \text { birds on a branch and some fly } \\
\text { away. If there are } 3 \text { birds left on the branch, } \\
\text { how many birds have flown away? }\end{array}$ & Change \\
\hline
\end{tabular}


Table 2. Cont.

\begin{tabular}{|c|c|c|c|}
\hline TYPE & ITEM & EXAMPLE & PART REQUESTED IN THE RESOLUTION \\
\hline Change 6 & 2 & $\begin{array}{c}\text { Juan has got } 4 \text { cherries and eats } 2 . \text { How many } \\
\text { cherries are left? }\end{array}$ & Result \\
\hline Change 6 & 4 & $\begin{array}{c}\text { Sofía has got } 5 \text { marbles and loses } 3 \text { playing. } \\
\text { How many are left? }\end{array}$ & Result \\
\hline Combination 1 & 9 & $\begin{array}{l}\text { There are } 8 \text { balls in a box. Some are white and } \\
\text { others are black. If there are } 6 \text { black balls, how } \\
\text { many white balls are there? }\end{array}$ & Beginning/Part \\
\hline Combination & 19 & $\begin{array}{c}\text { Francisco has got } 4 \text { books. Pablo has some. The } \\
\text { two of them have } 9 \text { stories altogether. How } \\
\text { many stories does Pablo have? }\end{array}$ & Middle/Part \\
\hline Comparation 1 & 12 & $\begin{array}{c}\text { Julio has got } 16 \text { books. He has } 4 \text { books more } \\
\text { than María. How many books does } \\
\text { María have? }\end{array}$ & Referent \\
\hline Comparation 1 & 14 & $\begin{array}{l}\text { In Juan's team, there are } 9 \text { children. There are } \\
5 \text { children more than in Luis's team. How } \\
\text { many children are there in Luis' team? }\end{array}$ & Referent \\
\hline Comparison 3 & 20 & $\begin{array}{c}\text { Manuel has got } 9 \text { cars. Jaime has got } 7 \text { more } \\
\text { than Manuel. How many cars does } \\
\text { Jaime have? }\end{array}$ & Comparison \\
\hline Comparison 4 & 13 & $\begin{array}{l}\text { Ana posted } 6 \text { cards. She posted } 3 \text { cards less } \\
\text { than Pablo. How many cards did she posted? }\end{array}$ & Referent \\
\hline Comparison 4 & 15 & $\begin{array}{l}\text { Mili has } 20 \text { coins. She has } 8 \text { less than Cristina. } \\
\text { How many coins does Cristina have? }\end{array}$ & Referent \\
\hline Comparison 5 & 16 & $\begin{array}{c}\text { Pedro has got } 5 \text { candies and María has got } 9 . \\
\text { How many candies does Pedro have less } \\
\text { than María? }\end{array}$ & Difference \\
\hline Equalization 1 & 5 & $\begin{array}{c}\text { Marta has got } 9 \text { balloons. If someone gives } \\
\text { Eduardo } 4 \text { balloons, he will have the same as } \\
\text { Marta. How many balloons will } \\
\text { Eduardo have? }\end{array}$ & Equal unknown set \\
\hline Equalization 2 & 17 & $\begin{array}{l}\text { There are } 7 \text { cakes on the table and } 14 \text { children } \\
\text { around it. How many cakes should we add for } \\
\text { each child to eat a cake? }\end{array}$ & Unknown equalization \\
\hline Equalization 5 & 18 & $\begin{array}{l}\text { María has got } 8 \text { crayons. Her brother has got } 5 \text {. } \\
\text { How many crayons should María lose to have } \\
\text { the same number as her brother? }\end{array}$ & Unknown equalization \\
\hline Equalization 6 & 8 & $\begin{array}{l}\text { Javi has got } 9 \text { marbles. If he lost } 6 \text { marbles, he } \\
\text { would have the same number of marbles as } \\
\text { Tomás. How many marbles does Tomás have? }\end{array}$ & Equal unknown set \\
\hline
\end{tabular}

This test was conducted in Spanish, the language of instruction used to teach mathematics, to those students who were taught mathematics in that language, and in English language to students who were taught in English. The problems were translated from Spanish into English following the translational procedure established for such a purpose.

During the school day we first handed out two collective tests ( 1 and 2 ) to the groups in their usual classrooms. We then assessed the students individually according to the language of instruction in their school where they are taught mathematics. Then students were assessed in a different room from their usual classroom. First grade students were evaluated first, and then the students who belonged to 2 nd grade. We carried out the tests individually over two consecutive days counterbalancing the order of the tests ( 1 y 2$)$ across groups. Each session lasted approximately $30 \mathrm{~min}$, depending on each student's performance. 


\section{Results}

Data analysis was carried out using the SPSS (version 25.0, IBM Corporation, Armonk, New York, USA) statistical package. In Table 3 is shown the number of participants who did the problems correctly, and those who did not solved them correctly.

Table 3. Distribution of students per grade (1st and 2nd graders), mother tongue/language of instruction and wrong/right answer.

\begin{tabular}{|c|c|c|c|c|c|c|c|c|c|c|c|c|c|c|c|c|c|c|c|c|c|}
\hline \multicolumn{22}{|c|}{ 1st Grade } \\
\hline Problems & & 1 & 2 & 3 & 4 & 5 & 6 & 7 & 8 & 9 & 10 & 11 & 12 & 13 & 14 & 15 & 16 & 17 & 18 & 19 & 20 \\
\hline \multirow{3}{*}{ Differ. Language } & Error & 2 & 9 & 3 & 10 & 34 & 29 & 20 & 21 & 32 & 23 & 24 & 24 & 35 & 35 & 27 & 21 & 27 & 19 & 32 & 28 \\
\hline & Right & 42 & 35 & 41 & 34 & 10 & 15 & 24 & 23 & 12 & 21 & 20 & 20 & 9 & 9 & 17 & 23 & 17 & 25 & 12 & 16 \\
\hline & Total & 44 & 44 & 44 & 44 & 44 & 44 & 44 & 44 & 44 & 44 & 44 & 44 & 44 & 44 & 44 & 44 & 44 & 44 & 44 & 44 \\
\hline \multirow{3}{*}{ Same Language } & Error & 0 & 1 & 9 & 2 & 30 & 13 & 5 & 14 & 22 & 12 & 6 & 10 & 27 & 22 & 23 & 15 & 17 & 9 & 19 & 22 \\
\hline & Right & 36 & 35 & 27 & 34 & 6 & 23 & 31 & 22 & 14 & 24 & 30 & 26 & 9 & 14 & 13 & 21 & 19 & 27 & 17 & 14 \\
\hline & Total & 36 & 36 & 36 & 36 & 36 & 36 & 36 & 36 & 36 & 36 & 36 & 36 & 36 & 36 & 36 & 36 & 36 & 36 & 36 & 36 \\
\hline \multicolumn{22}{|c|}{ 2nd Grade } \\
\hline Problems & & 1 & 2 & 3 & 4 & 5 & 6 & 7 & 8 & 9 & 10 & 11 & 12 & 13 & 14 & 15 & 16 & 17 & 18 & 19 & 20 \\
\hline \multirow{3}{*}{ Differ. Language } & Error & 1 & 7 & 2 & 7 & 34 & 20 & 12 & 18 & 20 & 19 & 18 & 16 & 28 & 31 & 26 & 17 & 24 & 12 & 30 & 18 \\
\hline & Right & 48 & 42 & 47 & 42 & 15 & 29 & 37 & 31 & 29 & 30 & 31 & 33 & 21 & 18 & 23 & 32 & 25 & 37 & 19 & 31 \\
\hline & Total & 49 & 49 & 49 & 49 & 49 & 49 & 49 & 49 & 49 & 49 & 49 & 49 & 49 & 49 & 49 & 49 & 49 & 49 & 49 & 49 \\
\hline \multirow{3}{*}{ Same Language } & Error & 1 & 4 & 2 & 4 & 18 & 11 & 9 & 19 & 9 & 11 & 7 & 11 & 20 & 22 & 17 & 17 & 16 & 13 & 16 & 13 \\
\hline & Right & 39 & 36 & 38 & 36 & 22 & 29 & 31 & 21 & 31 & 29 & 33 & 29 & 20 & 18 & 23 & 23 & 24 & 27 & 24 & 27 \\
\hline & Total & 40 & 40 & 40 & 40 & 40 & 40 & 40 & 40 & 40 & 40 & 40 & 40 & 40 & 40 & 40 & 40 & 40 & 40 & 40 & 40 \\
\hline
\end{tabular}

In order to evaluate the possible differences between the use of the language of instruction versus the use of mother tongue, the Pearson chi-square hypothesis contrast test $\left(\mathrm{X}^{2}\right)$ was performed for each of the problems in both 1st and 2nd grades. When breaking down the results (see Table 4) and emphasizing the statistically significant differences, they appeared with statistically higher values when there was a similarity between the native language and the language of instruction. However, the values were not higher when the mother tongue and the language used for instruction were different. On one hand, in 1st grade, there were statistically significant differences in the items 2 $\left(\mathrm{X}^{2}(1, N=80)=5657, p=0.017\right), 3\left(\mathrm{X}^{2}{ }_{(1, N=80)}=5134, p=0.023\right), 4\left(\mathrm{X}_{(1, N=80)}=4579, p=0.032\right)$, $6\left(\mathrm{X}^{2}(1, N=80)=7050, p=0.008\right), 7\left(\mathrm{X}_{(1, N=80)}=9183, p=0.002\right), 11\left(\mathrm{X}_{(1, N=80)}^{2}=12.121\right.$, $p=0.000), \mathrm{y} 12\left(X^{2}(1, N=80)=5805, p=0.016\right)$. On the other hand, in 2nd grade all these differences disappeared, leaving only that of item $11\left(X^{2}(1, N=89)=5392, p=0.045\right)$, and significant differences appearing in the items $\left.5\left(X^{2}{ }_{(1, N}=89\right)=5392, p=0.020\right)$, and $19\left(X^{2}{ }_{(1, N=89)}=3973\right.$, $p=0.046)$.

In the same way, all 20 items were grouped according to three characteristics (see Table 5): the type of problem (change, equalization, combination or comparison), location of the unknown (result, mean, beginning), and if it was an addition or subtraction problem.

The last objective was to determine if the language coincidence (the language of instruction was the same as the mother tongue) showed higher values compared to the situation when this coincidence did not occur. The differences between both groups denote better results when the languages coincide than when languages are different (see Table 6).

In 1st grade groups we found statistically significant differences (see Table 7) when solving exchange problems $\left(Z_{(48, N=80)}=3849, p=0.000\right)$, particularly in those problems with medium unknown $\left(Z_{(1, N=80)}=2625, p=0.009\right)$ and beginning unknown $\left(Z_{(1, N=80)}=2706, p=0.007\right)$, and also both in additions $\left(Z_{(1, N=80)}=2150, p=0.032\right)$ and subtractions $\left(Z_{(1, N=80)}=2708, p=0.007\right)$. In 2 nd grade groups, all these differences disappeared, and they only remained if they were additions $\left(Z_{(1, N=89)}=2113, p=0.035\right)$. We also found differences when they were combination problems $\left(Z_{(1, N=89)}=2530, p=0.011\right)$. 
Table 4. Differences in problem solving based on the coincidence or lack of coincidence between the first language and the language of instruction.

\begin{tabular}{|c|c|c|c|c|c|c|c|c|c|c|}
\hline \multicolumn{11}{|c|}{ 1st Grade } \\
\hline Problem & 1 & 2 & 3 & 4 & 5 & 6 & 7 & 8 & 9 & 10 \\
\hline $\begin{array}{c}\text { Chi- } \\
\text { square }\end{array}$ & 1678 & 5657 & 5134 & 4579 & 0.455 & 7050 & 9183 & 0.629 & 1218 & 2886 \\
\hline Sig. & 0.195 & $0.017 *$ & $0.023 *$ & $0.032 *$ & 0.500 & $0.008 *$ & $0.002 *$ & 0.428 & 0.270 & 0.089 \\
\hline Problem & 11 & 12 & 13 & 14 & 15 & 16 & 17 & 18 & 19 & 20 \\
\hline $\begin{array}{c}\text { Chi- } \\
\text { square }\end{array}$ & 12.121 & 5805 & 0.235 & 3285 & 0.054 & 0.294 & 1600 & 2877 & 3410 & 0.054 \\
\hline Sig. & 0.000 * & 0.016 * & 0.628 & 0.070 & 0.816 & 0.588 & 0.206 & 0.090 & 0.065 & 0.816 \\
\hline \multicolumn{11}{|c|}{ 2nd Grade } \\
\hline Problem & 1 & 2 & 3 & 4 & 5 & 6 & 7 & 8 & 9 & 10 \\
\hline $\begin{array}{c}\text { Chi- } \\
\text { square }\end{array}$ & 0.021 & 0.373 & 0.043 & 0.373 & 5392 & 1720 & 0.048 & 1051 & 3363 & 1253 \\
\hline Sig. & 0.884 & 0.541 & 0.835 & 0.541 & 0.020 * & 0.190 & 0.826 & 0.305 & 0.067 & 0.263 \\
\hline Problem & 11 & 12 & 13 & 14 & 15 & 16 & 17 & 18 & 19 & 20 \\
\hline $\begin{array}{c}\text { Chi- } \\
\text { square }\end{array}$ & 4034 & 0.277 & 0.452 & 0.625 & 0.984 & 0.568 & 0.718 & 0.700 & 3973 & 0.174 \\
\hline Sig. & $0.045^{*}$ & 0.599 & 0.501 & 0.429 & 0.321 & 0.451 & 0.397 & 0.403 & $0.046^{*}$ & 0.677 \\
\hline
\end{tabular}

${ }^{*}$ Chi-square statistic is significant at the level 0.05 .

Table 5. Summary of the groupings according to the type of problem.

\begin{tabular}{|c|c|c|c|c|c|c|c|c|c|c|c|c|c|c|c|c|c|c|c|c|c|}
\hline & Problem & 1 & 2 & 3 & 4 & 5 & 6 & 7 & 8 & 9 & 10 & 11 & 12 & 13 & 14 & 15 & 16 & 17 & 18 & 19 & 20 \\
\hline \multirow{4}{*}{ Type } & Change & $x$ & $\mathrm{x}$ & $x$ & $x$ & & $x$ & $x$ & & & $x$ & $x$ & & & & & & & & & \\
\hline & Equalization & & & & & $\mathrm{x}$ & & & $x$ & & & & & & & & & $x$ & $x$ & & \\
\hline & Combination & & & & & & & & & $x$ & & & & & & & & & & $\mathrm{x}$ & \\
\hline & Comparison & & & & & & & & & & & & $x$ & $x$ & $x$ & $\mathrm{x}$ & $x$ & & & & $x$ \\
\hline \multirow{3}{*}{ Unknown } & Result & $x$ & $\mathrm{x}$ & $\mathrm{x}$ & $x$ & $x$ & & & $\mathrm{x}$ & & & & & & & & & & & & $x$ \\
\hline & Medium & & & & & & $x$ & $x$ & & $x$ & & & & & & & $x$ & $x$ & $x$ & $x$ & \\
\hline & Beginning & & & & & & & & & & $\mathrm{x}$ & $\mathrm{x}$ & $\mathrm{x}$ & $\mathrm{x}$ & $\mathrm{x}$ & $\mathrm{x}$ & & & & & \\
\hline \multirow{2}{*}{ Add/Subtract } & Addition & $x$ & & $x$ & & $x$ & $x$ & & & $x$ & & & $\mathrm{x}$ & & $\mathrm{x}$ & & & $x$ & & $\mathrm{x}$ & $x$ \\
\hline & Subtraction & & $x$ & & $x$ & & & $x$ & $x$ & & $x$ & $x$ & & $x$ & & $x$ & $x$ & & $x$ & & \\
\hline
\end{tabular}

Table 6. Descriptive statistics by language coincidence (yes/no) (M: mean; SD: standard deviation).

\begin{tabular}{|c|c|c|c|c|c|c|c|}
\hline \multicolumn{8}{|c|}{ 1st Grade } \\
\hline & & & $\mathbf{n}$ & $\mathbf{M}$ & SD & Mín. & Máx. \\
\hline \multirow{8}{*}{ Type } & \multirow{2}{*}{ Change } & no language of instruction & 44 & 5.27 & 1.65 & 2 & 8 \\
\hline & & language of instruction & 36 & 6.67 & 1.15 & 4 & 8 \\
\hline & \multirow{2}{*}{ Equalization } & no language of instruction & 44 & 1.70 & 1.27 & 0 & 4 \\
\hline & & language of instruction & 36 & 2.06 & 1.07 & 0 & 4 \\
\hline & \multirow{2}{*}{ Combination } & no language of instruction & 44 & 0.55 & 0.76 & 0 & 2 \\
\hline & & language of instruction & 36 & 0.86 & 0.80 & 0 & 2 \\
\hline & \multirow{2}{*}{ Comparison } & no language of instruction & 44 & 2.14 & 1.86 & 0 & 6 \\
\hline & & language of instruction & 36 & 2.69 & 1.67 & 0 & 6 \\
\hline \multirow{6}{*}{ Unknown } & \multirow{2}{*}{ Result } & no language of instruction & 44 & 4.57 & 1.39 & 2 & 7 \\
\hline & & language of instruction & 36 & 4.83 & 1.28 & 2 & 7 \\
\hline & \multirow{2}{*}{ Medium } & no language of instruction & 44 & 2.91 & 2.23 & 0 & 7 \\
\hline & & language of instruction & 36 & 4.22 & 1.94 & 0 & 7 \\
\hline & \multirow{2}{*}{ Beginning } & no language of instruction & 44 & 2.18 & 1.56 & 0 & 5 \\
\hline & & language of instruction & 36 & 3.22 & 1.55 & 1 & 6 \\
\hline
\end{tabular}


Table 6. Cont.

\begin{tabular}{|c|c|c|c|c|c|c|c|}
\hline \multicolumn{8}{|c|}{ 1st Grade } \\
\hline \multirow{4}{*}{ Add/subtract } & \multirow{2}{*}{ Addition } & no language of instruction & 44 & 4.41 & 2.06 & 2 & 9 \\
\hline & & language of instruction & 36 & 5.44 & 2.21 & 1 & 10 \\
\hline & \multirow{2}{*}{ Subtraction } & no language of instruction & 44 & 5.25 & 2.61 & 0 & 10 \\
\hline & & language of instruction & 36 & 6.83 & 2.09 & 2 & 10 \\
\hline \multicolumn{8}{|c|}{ 2nd Grade } \\
\hline & & & $\mathbf{n}$ & $\mathbf{M}$ & SD & Mín. & Máx. \\
\hline \multirow{8}{*}{ Type } & \multirow{2}{*}{ Change } & no language of instruction & 49 & 6.24 & 1.61 & 3 & 8 \\
\hline & & language of instruction & 40 & 6.78 & 1.48 & 3 & 8 \\
\hline & \multirow{2}{*}{ Equalization } & no language of instruction & 49 & 2.20 & 1.12 & 0 & 4 \\
\hline & & language of instruction & 40 & 2.35 & 1.23 & 0 & 4 \\
\hline & \multirow[b]{2}{*}{ Combination } & no language of instruction & 49 & 0.98 & 0.72 & 0 & 2 \\
\hline & & language of instruction & 40 & 1.38 & 0.77 & 0 & 2 \\
\hline & \multirow{2}{*}{ Comparison } & no language of instruction & 49 & 3.22 & 1.62 & 0 & 6 \\
\hline & & language of instruction & 40 & 3.50 & 1.65 & 0 & 6 \\
\hline \multirow{6}{*}{ Unknown } & \multirow[b]{2}{*}{ Result } & no language of instruction & 49 & 5.22 & 1.48 & 2 & 7 \\
\hline & & language of instruction & 40 & 5.48 & 1.22 & 2 & 7 \\
\hline & \multirow{2}{*}{ Medium } & no language of instruction & 49 & 4.24 & 2.07 & 0 & 7 \\
\hline & & language of instruction & 40 & 4.73 & 2.23 & 0 & 7 \\
\hline & \multirow{2}{*}{ Beginning } & no language of instruction & 49 & 3.18 & 1.51 & 0 & 6 \\
\hline & & language of instruction & 40 & 3.80 & 1.57 & 0 & 6 \\
\hline \multirow{4}{*}{ Add/subtract } & \multirow{2}{*}{ Addition } & no language of instruction & 49 & 6.00 & 2.11 & 2 & 10 \\
\hline & & language of instruction & 40 & 7.03 & 2.24 & 3 & 10 \\
\hline & \multirow{2}{*}{ Subtraction } & no language of instruction & 49 & 6.65 & 2.39 & 1 & 10 \\
\hline & & language of instruction & 40 & 6.98 & 2.35 & 2 & 10 \\
\hline
\end{tabular}

Table 7. Effects of the types of problems by language coincidence (yes/no).

\begin{tabular}{|c|c|c|c|c|c|c|c|c|c|}
\hline \multicolumn{10}{|c|}{ 1st Grade } \\
\hline & \multicolumn{4}{|c|}{ Type } & \multicolumn{3}{|c|}{ Unknown } & \multicolumn{2}{|c|}{ Addition/Subtraction } \\
\hline & Change & Equalization & Combination & Comparison & Result & Medium & Beginning & Addition & Subtraction \\
\hline $\mathrm{Z}$ & 3849 & 1122 & 1880 & 1412 & 0.803 & 2625 & 2706 & 2150 & 2708 \\
\hline Sig. & 0.000 & 0.262 & 0.060 & 0.158 & 0.422 & 0.009 & 0.007 & 0.032 & 0.007 \\
\hline \multicolumn{10}{|c|}{ 2nd Grade } \\
\hline & \multicolumn{4}{|c|}{ Type } & \multicolumn{3}{|c|}{ Unknown } & \multicolumn{2}{|c|}{ Addition/Subtraction } \\
\hline & Change & Equalization & Combination & Comparison & Result & Medium & Beginning & Addition & Subtraction \\
\hline $\mathrm{Z}$ & 1654 & 0.459 & 2530 & 0.718 & 0.570 & 1278 & 1885 & 2113 & 0.621 \\
\hline Sig. & 0.098 & 0.646 & 0.011 & 0.473 & 0.569 & 0.201 & 0.059 & 0.035 & 0.535 \\
\hline
\end{tabular}

\section{Discussion}

Our main aim was to determine if the language of instruction influenced the resolution of verbal problems when it coincided or was different from the students' mother tongue. In order to define the scope of our data, we divided the analysis into two large sections: (a) analysis of correct answers and (b) analysis of resolution procedures, i.e., the errors and proportion of correct answers.

From this moment onward, we used several labels to refer to the groups. The 1st grade group whose language of instruction did not coincide with their first language, that is, noncoincident language of instruction, was called G-I, whereas the group whose language does coincide, was called G-II. In the 2 nd grade groups, the group with the noncoincident 
language of instruction was called G-III, whereas the group whose language coincided with the instruction language, was called G-IV.

(a) Analysis of correct answers.

The results showed that in the 1st grade groups there were significant differences only in the type of exchange problems. If we take into account this variable, we can observe that there was a higher percentage of correct answers in group G-II compared to G-I in all types of problems, but this difference was statistically significant only in exchange problems.

The situation where we found more differences in one of the problems with less difficulty such as exchange problems $[29,38-40,49-54]$ may be due to the fact that students using their mother tongue were more capable of creating a prepositional base text which allowed them to be able to construct problem models, while the students who solved it in a nondominant language or noncoincident language of instruction, needed more time to construct these models. We observed that in all types of problems, students with the coincident language showed higher performance, and both in G-I and G-II, students efficiency when solving equalization and comparison problems was lower compared to those of change and combination types. Therefore, we can claim that there are only significant differences between the groups in exchange problems.

This tendency was maintained in the 2nd grade groups when problems had a simpler linguistic structure, such as in change and combination types. We observed that the GIII's resolution was lower if compared to G-IV, being more significant in combination problems. However, these differences became shorter in equalization and comparison verbal problems.

Similarly, in both 1st and 2nd grades, we found that the most significant differences occurred in those problems whose semantic structure was simpler. This could be due to the fact that when the performance is higher the distances increase, but if the difficulty of the problems increases, students' performance decreases and the differences in problem solving are not so important. In this sense, it is based on those theories supporting the idea that problems are encoded in memory under a verbal format [23,55-57], that is, when this encoding is carried out in a nondominant language, there tends to be greater difficulty in its recovery $[2,58,59]$. For this reason, in problems whose semantic structure is simpler, the child encodes more easily in his dominant language than in his nondominant language, hence his performance is higher. However, with those problems whose linguistic structure is more complex, the coding is also much more complex. Therefore, it is always less difficult in the dominant language.

Accordingly, problem solving would not only involve verbal processes in data retrieval but also in the application of the resolution procedures [60-62]. These authors highlight that the components of working memory are necessary to manage the successive steps of the complex resolution procedure and that these components could be at least partially verbal in nature, which would also explain a lower performance in students who solve these tasks in their nondominant language.

From our point of view, if more significant differences appeared in the 1st grade groups compared to the 2nd grade groups, it would result from the limitation of exposure time to this type of tasks, which had not allowed, for the moment, the construction of structures or models to solve the problems that help balance the difficulties they had at a linguistic level. Such difficulties could be derived from the fact that the linguistic structure presented provided a great semantic load and served as a support for the representation and the relationship between the concepts. This seemed to be reinforced when more specific and less efficient strategies were used since they had a medium level of linguistic performance [62].

If we analyze the correct answers considering the location of the unknown, we can observe that in 1st graders, when the unknown was located in first or second position there were significant differences, highlighting that G-II students' performance was higher compared to G-I. Similarly, when the unknown was located in third position, the G-II mean was again slightly higher, although no significant differences were found. 
All students demonstrated higher performance when the unknown was in third position with respect to the first and second position, which generally confirmed the data found in other investigations $[29,51,63]$. Therefore, we can point out that the problems that were more difficult to solve depending on the location of the unknown were also a relevant fact: the group whose dominant language coincided with the language of instruction obtained higher performance. Once again, we could be faced with a linguistic-based difficulty, as in order for the students to solve this type of problems they had to "translate" the problem into a simpler way by exchanging the place of the addends. In this process, both verbal and mathematical components were again involved, hence the lack of mastery in one of them could have an effect on the resolution.

In the 2nd grade groups the contrasts in the different positions of the unknown were not significant, although G-IV students presented higher means than the group that did not coincide in all positions.

As previously mentioned, all 2nd graders also showed higher performance when the unknown was located in the third position compared to the other two groups. In other words, regardless of the age group, the level of difficulty of the tasks decreased when the third term was unknown; however, it increased when the second term was unknown, and even with greater intensity if the first term was unknown.

If we compare the differences established between the 1st and 2nd grade groups with respect to the location of the unknown, we see that in the 2nd grade groups it is less noticeable, which reinforces the idea that showing students this type of tasks can allow them to construct models and strategies that compensate for their difficulties in language proficiency. The reason could be that the resolution models in a second language follow a similar structure to the resolution in the mother tongue concerning both the linguistic structure of the problem and the place of the unknown. In this sense, the problems of change and combination were better resolved in both groups, regardless of the language of instruction, than the problems of comparison and equalization. Likewise, in the problems where the unknown appeared in first place, the execution level was lower than when it appeared in the result.

(b) Analysis of resolution procedures.

First of all, we describe which were the most frequent errors in each group, and secondly, we give a broader and more global explanation. Our main aim is to determine if a certain type of error is associated with a certain problem, or if it depends on the location of the unknown, and if that error is corrected when the mother tongue coincides or not with the language of instruction.

One of the first conclusions that we can draw (see Table 3) is that the different categories of problems cannot be associated with a specific type of error. This can be highlighted because we can find several prevailing errors in each group who worked on some of the problems sharing the same category. Neither can we establish a model based on the typical errors committed by pupils. However, as it has been pointed out in other investigations [13,40,47,50-52] errors such as "repeating one of the quantities" and "inventing the answer" are more frequent in 1st grade than in 2nd graders, who generate other types of errors such as "transforming the problem" and "keyword". It must be highlighted that this last error is closely linked to the semantic component of the problem, and in both Spanish and English it has similarities "más que" or "more than". For this reason, this error has repeatedly been shown in all groups mostly in the majority of problems of Comparison 1 and 4 .

Transforming the problem is another type of error that tends to appear in 2nd grade groups. It also appears in 1st grade groups when the level of language comprehension is higher when solving problems in their dominant language. In these cases, students tend to make modifications to the problem in order to make it simpler. It generally occurs in those problems of which the unknown is not found in the result. This indicates that students show a greater understanding of the linguistic component within the problem. It, therefore, 
would not appear in G-I group whose linguistic proficiency is low and the time of exposure to this task has also been more limited.

It is relevant to note that execution errors have occurred in the simplest problems such as that of exchange, where the linguistic structure or the place of the unknown has changed the type of error. However, we can note that the error has been mostly conceptual.

In problems with a medium difficulty such as problems of change 2 , we observe that in the 1st grade group (G-I) whose mother tongue does not coincide with the language of instruction, the most frequent error they made was not understanding the problem. However, students with a second dominant language, or 2nd grade groups who had already been exposed to this type of task, tended to transform the problem. This way, we can confirm that this is supporting the theory of creating models that allow linguistic difficulties to be overcome.

Most importantly, we can note that the possibility of committing errors diminished in all problems as students' ages were higher, as was also demonstrated in other studies such as Carpenter and Moser [53], and Bermejo [64]. In this sense, we can see that the higher the students' grade, the less significant the differences in errors committed. There were significant differences in the problems of change $(2,3,4,5,6)$ and comparison 1 in 1 st grade groups, with G-I being the group making a higher number of errors. However, group G-II made a higher number of errors in the change 3 problem, making up a large part of execution.

In the 2nd grade groups, there was a high decline of significant differences in errors, repeating the errors in the change 2 type and appearing in equalization 1 and change 4 . In this case, G-III continued to commit a higher number of errors than G-IV.

Furthermore, it should be emphasized that, on many occasions the percentage of errors produced by G-II in the same problem was similar to the percentage of G-III. This suggests that, although there was only a difference of one school year between both groups, the linguistic proficiency of the verbal structure in 1st graders could make the problem execution more difficult. Therefore, the performance in problem solving by those groups whose language is dominant in both their mother tongue and the language of instruction, compared to those that is not, may be close to a lag of one school year.

\section{Conclusions}

The results of this study reassert the existing relationship between language and the verbal problem-solving tasks in mathematics. We can also see the effects that the second language has on these types of tasks as well as how that influence is evolving throughout the different grades.

It has been demonstrated that as students obtained a greater command of the language and had more exposure to solving problems in a second language, their performance improved, although it did not reach the same level as their resolution performance in their dominant language.

We could also observe how translanguaging took place on many occasions. Through their first language they were capable of resolving a verbal problem, in some cases by giving the answer in the dominant language, and in other cases by translating the problem into their dominant language to have a better understanding of it. Then the answer was translated back from Spanish into English to provide the answer. In this way, we observed that the change of code from one language to another was done using their mother tongue when a complicated linguistic or semantic structure was provided and providing the answer immediately in the second language or English (i.e., the language that was being used for the resolution of the problem).

Likewise, errors tended to decrease as the age of the students increased, although the difference between the dominant and nondominant language groups was close to one school year. It was also observed that the nature of the errors was modified, and although errors remained conceptual, on many occasions they denoted that there was a 
certain understanding of the semantic structure of the problem, which led the students to transform it or use "keywords".

We highlight the importance of establishing strategies that would allow the child to overcome the linguistic difficulties that can occur in the first stages of learning a second language. In this way, we would also help students who show difficulties in their first language. We propose the use of images or pictorial representations that can help the students to make it by themselves; these materials can help them understand the situation and make easier the process of transferring the knowledge in the language of instruction. Concerning teaching mathematics, studies suggest that a low performance in multilingual students can be partly, and even totally, due to their language limitations. For instance, the existing performance differences disappeared between speakers of German as a first and second language when problems were presented symbolically rather than verbally [65].

We must bear in mind that this study has been carried out in international schools specialized in the area of second language acquisition as well as in CLIL. However, in schools that do not reach such a degree of specialization in these two areas, it would be necessary, before implementing bilingual programs, to reflect on the availability of resources and the development of teacher training.

The language of instruction seems to determine its use in the processes involved in teaching in later grades and even in adult life [56,66-68], therefore it is essential to solve all difficulties and encourage its transfer and use at early ages. It should be taken into account in those schools that are implementing bilingual programs. In addition, teachers in bilingual contexts should be encouraged to be aware of both the problems associated with language and cultural awareness in a very sensitive way, which will allow them to value all the previous knowledge that the student brings to the classroom. Likewise, teachers should also provide students with equal opportunities and promote the exchange of ideas, avoiding any language difficulty so that all students can develop the same mathematical competence [69].

Additionally, it would be interesting to carry out similar studies in immersion programs evaluating a higher number of participants, to study teachers' perceptions towards the students' linguistic difficulties and their attitudes in the classroom in order to favor all students' inclusion, regardless of their linguistic competence. Therefore, if these studies were carried out in ordinary centers whose level of interculturality is lower, we could obtain a different approach that would complement the results shown in this article.

For future research, it would also be adequate to address the didactic aspects and educational strategies that can favor the transfer of knowledge from and to the language of instruction and mathematical concepts, as well as the linguistic aids that students may need to successfully address the challenges posed by the teaching of mathematic in a second language.

Author Contributions: Performed the research and wrote the paper, P.E. and I.M.; performed the method, statistical analyses and designed the research, Á.M.; reviewed and completed the article, V.B. All authors have read and agreed to the published version of the manuscript.

Funding: This work was not funded.

Institutional Review Board Statement: The study was conducted according to the guidelines of the Declaration of Helsinki.

Informed Consent Statement: Informed consent was obtained from all subjects involved in the study.

Data Availability Statement: Not applicable.

Conflicts of Interest: The authors declare that the research was conducted in the absence of any commercial or financial relationships that could be construed as a potential conflict of interest. 


\section{References}

1. Barwell, R.; Clarkson, P.; Halai, A.; Kazima, M.; Moschkovich, J.N.; Planas, N.; Phakeng, M.; Valero, P.; Villavicencio Ubillús, M. Mathematics Education and Language Diversity. The 21st ICMI Study; Springer International Publishing: Berlin, Germany, 2009.

2. Van Rinsveld, A.; Schiltz, C.; Brunner, M.; Lander, K.; Ugen, S. Solving Arithmetic Problems in First and Second Language: Does the Language Context Matter? Learn. Inst. 2016, 42, 72-82. [CrossRef]

3. Bloomfield, L. Language; Allen and Unwin: London, UK, 1933.

4. Planas, N. Hacia Una Noción Situada de Lengua Para la Educación Matemática. Rev. Latinoam Etnomatemática $2014,7,151-169$.

5. Cummins, J. The Influence of Bilingualism on Cognitive Growth: A Synthesis of Research Findings and Explanatory Hypotheses. Work. Pap. Biling. 1976, 9, 1-43.

6. Hakuta, K.; Díaz, R.M. The Relationship Between Degree of Bilingualism and Cognitive Ability: A Critical Discussion and Some New Longitudinal Data. Children's Lang. 1985, 5, 319-344.

7. De Houwer, A. By Way of Introduction: Methods and Studies of Bilingual First Language Acquisition. Int. J. Biling 1998, 2, 249-263. [CrossRef]

8. Cummins, J. Language, Power and Pedagogy: Bilingual Children in the Crossfire; Multilingual Matters: Bristol, UK; Buffalo, NY, USA, 2000.

9. Wal-Pastoor, L. Discourse and Learning in a Norwegian Multiethnic Classroom: Developing Shared Understanding Through Classroom Discourse. Eur. J. Psychol. Educ. 2005, 20, 13-27. [CrossRef]

10. Barwell, R.; Chapsam, L.; Nkambule, T.; Phakeng, M.S. Tensions in Teaching Mathematics in Contexts of Language. In Mathematics Education and Language Diversity; Springer: Cham, Switzerland, 2016; pp. 175-192. [CrossRef]

11. Barton, B. Preface to "Ethnomathematics and Philosophy". In Towards Equity in Mathematics Education; Forgasz, H., Rivera, F.D., Eds.; Springer: Berlin, Germany, 2012; pp. 227-229.

12. Cummins, J. Bilingualism and Special Education: Issues in Assessment and Pedagogy; Multilingual Matters: Bristol, UK; Buffalo, NY, USA, 1984.

13. Cummins, J. Interdependence of First- and Second-Language Proficiency in Bilingual Children. In Language Processing in Bilingual Children; Cambridge University Press: Cambridge, MA, USA, 1991; pp. 70-89.

14. Imedazde, N. On the Psychological Nature of Child Speech Formation Under the Condition of Exposure to Two Languages. Int. J. Psychol. 1967, 2, 129-132. [CrossRef]

15. García, O.; Li, W. Translanguaging: Language, Bilingualism and Education; Palgrave: London, UK, 2014.

16. Cenoz, J.; Gorter, D. Teaching English Through Pedagogical Translanguaging. World Engl. 2020, 39, 300-311. [CrossRef]

17. French-Mestre, C.; Vaid, J. Activation of Number Facts in Bilinguals. Mem. Cogn. 1993, 2l, 809-818. [CrossRef]

18. Geary, D.C.; Cormier, P.; Goggin, J.P.; Estrada, P.; Lunn, M.C.E. Mental Arithmetic: A Componential Analysis of Speed-ofProcessing Across Monolingual, Weak Bilingual, and Strong Bilingual Adults. Int. J. Psychol. 1993, 28, 185-201. [CrossRef]

19. Van Rinsveld, A.; Brunner, M.; Landerl, K.; Schiltz, C.; Ugen, S. The Relation Between Language and Arithmetic in Bilinguals: Insights from Different Stages of Language Acquisition. Front. Psychol. 2015, 6, 265. [CrossRef] [PubMed]

20. Gonzalez, E.G.; Kolers, P.A. Notational Constraints on Mental Operations. In Mathematics Dirabilitier: A Cognitive Neuroprychological Perrpective; Deloche, G., Seron, X., Eds.; Erlbaum: Washington, DC, USA, 1967; pp. 27-42.

21. Bernardo, A.B.I.; Calleja, M.O. The Effects of Stating Problems in Bilingual Students' First and Second Languages on Solving Mathematical Word Problems. J. Genet. Psychol. 2005, 166, 117-129. [CrossRef] [PubMed]

22. Dehaene, S. The Number Sense; Oxford University Press: Oxford, UK, 1997.

23. Dehaene, S. El Cerebro Matemático; Siglo Veintiuno Editors: Buenos Aires, Argentina, 2016.

24. McCloskey, M. Cognitive Mechanisms in Numerical Processing: Evidence from Acquired Dyscalculia. Cognition 1992, 44, $107-137$. [CrossRef]

25. Baker, C. Foundations of Bilingual Education and Bilingualism; Multilingual Matters: Bristol, UK; Buffalo, NY, USA, 2001.

26. García, O. Bilingual Education in the 21st Century: A Global Perspective; Wiley-Blackwell: New York, NY, USA, 2009.

27. Canagarajah, S. Translanguaging in the Classroom: Emerging Issues for Research and Pedagogy. Appl. Linguist. Rev. 2011, 2, 1-28. [CrossRef]

28. Li, W. Moment Analysis and Translanguaging Space: Discursive Construction of Identities by Multilingual Chinese Youth in Britain. J. Pragmat. 2011, 43, 1222-1235. [CrossRef]

29. Bermejo, V. Cómo Enseñar Matemáticas Para Aprender Mejor; CCS: Madrid, Spain, 2004.

30. Bofferding, L.; Richardson, S.E. Investigating Integer Addition and Subtraction: A Task Analysis. In Proceedings of the 35th Annual Meeting of the North American Chapter of the International Group for the Psychology of Mathematics Education; Martinez, M., Ed.; University of Illinois: Chicago, IL, USA, 2013; pp. 111-118.

31. Lamb, L.L.; Bishop, J.P.; Whitacre, I.; Philipp, R.A.; Schappelle, B.P.; Lewis, M. Seventh Grade Students' Performance and Ways of Reasoning: Integer Addition and Subtraction Problems. (White Paper). Retrieved from Center for Research in Mathematics and Science Education. 2017. Available online: http:/ / www.sci.sdsu.edu/CRMSE/projectz/documents/Integers\%207th\%20grade. pdf (accessed on 17 December 2020).

32. Vlassis, J. The Balance Model: Hindrance or Support for the Solving of Linear Equations with one Unknown. Educ. Stud. Math. 2002, 49, 341-359. [CrossRef]

33. Vlassis, J. The Role of Mathematical Symbols in the Development of Number Conceptualization: The case of the Minus Sign. Philos. Psychol. 2008, 21, 555-570. [CrossRef] 
34. Bishop, J.P.; Lamb, L.L.; Philipp, R.A.; Whitacre, I.; Schappelle, B.P. Using Order to Reason About Negative Numbers: The case of Violet. Educ. Stud. Math. 2014, 86, 39-59. [CrossRef]

35. Bofferding, L. Addition and Subtraction with Negatives: Acknowledging the Multiple Meanings of the Minus Sign. In Proceedings of the 32nd Annual Meeting of the North. American Chapter of the International Group for the Psychology of Mathematics Education; Brosnan, P., Erchick, D., Flevares, L., Eds.; The Ohio State University: Columbus, OH, USA, 2010; pp. 703-710.

36. Marian, V.; Fausey, C.M. Language Dependent Memory in Bilingual Learning. Appl. Cogn. Psychol. 2006, 20, 1025-1047. [CrossRef]

37. Kleemans, T.; Segers, E. Linguistic Precursors of Advanced Math Growth in First-Language and Second-Language Learners. Res. Dev. Disabil. 2020, 103. [CrossRef]

38. Bermejo, V.; Rodriguez, P. Estructura Semántica y Estrategias Infantiles en la Solución de Problemas Verbales de Adición. Infanc. Aprendiz. 1987, 39-40, 71-81. [CrossRef]

39. Carpenter, T.P.; Moser, J.M. The Development of Addition and Subtraction Problem Solving Skills. In Addition and Subtraction: A Cognitive Perspective; Carpenter, T.P., Moser, J.M., Romberg, T.A., Eds.; Erlbaum: Hillsdale, NJ, USA, 1982; pp. 9-24.

40. De Corte, E.; Verchaffel, L. The Effect of Semantic Structure on First Graders Strategies for Solving Addition and Subtraction Word Problem. J. Res. Math. Educ. 1987, 18, 363-381. [CrossRef]

41. Staub, F.C.; Reusser, K. The Role of Presentational Structures in Understanding and Solving Mathematical Word Problems. In Discourse Comprehension: Essays in Honor of Walter Kintsch; Weaver, C.A., Mannes, S., Fletcher, C.R., Eds.; Cambridge University Press: Cambridge, UK, 1995; pp. 285-305.

42. Orrantia, J. El Rol Del Conocimiento Conceptual en la Resolución de Problemas Aritméticos Con Estructura Aditiva. Infanc. Aprendiz. J. Stud. Educ. Dev. 2003, 26, 451-468. [CrossRef]

43. Bermejo, V.; Ester, P.; Morales, I. A Constructivist Intervention Program for the Improvement of Mathematical Performance Based on Empiric Developmental Results (PEIM). Front. Psychol. 2021, 11. [CrossRef] [PubMed]

44. Luevano, C.; Collins, T.A. Culturally Appropriate Math Problem-Solving Instruction with English Language Learners. Sch. Psychol. Rev. 2020, 492, 144-160. [CrossRef]

45. Raven, J.C.; Court, J.H.; Raven, J. Raven Matrices Progresivas; Escalas: Color (CPM), General (SPM), Superior (APM). Manual; TEA Ediciones, S.A.: Madrid, Spain, 1996.

46. Thurstone, L.L.; Yela, M. CARAS-R. Test. de Percepción de Diferencias-Revisado; Tea Ediciones: Madrid, Spain, 2012.

47. Bermejo, V.; Lago, M.O.; Rodríguez, P.; Dopico, C.; Lozano, J.M. PEI Un Programa de Intervención Para la Mejora del Rendimiento Matemático; Editorial Complutense, ES: Barcelona, Spain, 2002.

48. Bermejo, V.; Lago, M.O.; Rodríguez, P. Aprendizaje de la Adición y Sustracción. Secuenciación de los Problemas Verbales Según su Dificultad. Rev. Psicol. Gen. Appl. 1998, 51, 533-552.

49. Bebout, H. Children’s Symbolic Representation of Addition and Subtraction Word Problems. J. Res. Math. Educ. 1990, $21,123-131$. [CrossRef]

50. Bermejo, V.; Rodriguez, P. Relevancia de Algunos Factores en la Solución de Problemas Aditivos. Investig. Psicol. $1990,8,23-41$.

51. Bermejo, V.; Rodriguez, P. La Operación de Sumar. In El Niño y la Aritmética; Bermejo, V., Ed.; Paidós: Barcelona, Spain, 1990; pp. 107-140.

52. Carpenter, T.P.; Moser, J. The Acquisition of Addition and Subtraction Concepts. In Acquis. of Math.: Concepts and Process; Lesh, R., Landau, M., Eds.; Academic Press: New York, NY, USA, 1983; pp. 7-44.

53. Carpenter, T.P.; Moser, J.M. The Acquisition of Addition and Subtraction Concepts in Grades One Through Three. J. Res. Math. Educ. 1984, 15, 179. [CrossRef]

54. Castro, E. Resolución de Problemas: Ideas, Tendencias e Influencias en España. In Investigación en Educación Matemática XII; Luengo, R., Gómez, B., Camacho, M., Blanco, L., Eds.; Sociedad Española de Investigación en Educación Matemática: Barcelona, Spain, 2008; pp. 113-140.

55. Campbell, J.I.D. Architectures for Numerical Cognition. Cognition 1994, 531, 1-44. [CrossRef]

56. Campbell, J.I.; Epp, L.J. An Encoding-Complex Approach to Numerical Cognition in Chinese-English Bilinguals. Can. J. Exp. Psychol. 2004, 58, 229-244. [CrossRef]

57. Dehaene, S.; Cohen, L. Towards an Anatomical and Functional Model of Number Processing. Math. Cogn. 1995, 1, 83-120.

58. Spelke, E.; Tsivkin, S. Language and Number: A Bilingual Training Study. Cognition 2001, 78, 45-88. [CrossRef]

59. Saalbach, H.; Eckstein, D.; Andri, N.; Hobi, R.; Grabner, R.H. When Language of Instruction and Language of Application Differ: Cogn. Costs of Bilingual Mathematics Learning. Learn. Inst. 2013, 26, 36-44. [CrossRef]

60. Fürst, A.J.; Hitch, G.J. Separate Roles for Executive and Phonological Components of Working Memory in Mental Arithmetic. Mem. Cogn. 2000, 28, 774-782. [CrossRef] [PubMed]

61. LeFevre, J.-A.; Lei, Q.; Smith-Chant, B.L.; Mullins, D.B. Multiplication by Eye and by Ear for Chinese-Speaking and EnglishSpeaking Adults. Can. J. Exp. Psychol. 2001, 55, 277-284. [CrossRef] [PubMed]

62. Espinoza, L.; Marco, R.; Ygual-Fernández, A. Conciencia Fonológica y Resolución de Problemas Matemáticos en Educación Infantil. Revista de Logopedia Foniatría y Audiología 2017, 38, 61-68. [CrossRef]

63. Hiebert, J. The Position of Unknown Set in Children's Solution of Verbal Arithmetic Problems. J. Res. Math. Educ. 1982, 13, 341-349. [CrossRef]

64. Bermejo, V. Cómo y Cuándo el Niño Aprende las Matemáticas; Editorial Académica Española: Madrid, Spain, 2018. 
65. Heinze, A.; Herwartz-Emden, L.; Braun, C.; Reiss, K. Die Rolle von Kenntnissen der Unterrichtssprache beim Mathematiklernen. In Mathematiklernen Unter Bedingungen der Mehrsprachigkeit; Prediger, S., Özdil, E., Eds.; Waxmann: Münster, Germany, 2011; pp. 11-33.

66. Salillas, E.; Wicha, N.Y.Y. Early Learning Shapes the Memory Networks for Arithmetic: Evidence from Brain Potentials in Bilinguals. Psychol. Sci. 2012, 23, 745-755. [CrossRef]

67. Salillas, E.; Carreiras, M. Core Number Representations are Shaped by Language. Cortex 2014, 52, 1-11. [CrossRef]

68. Kollosche, D. Towards Guidelines for the Analysis of Teaching Materials in Linguistically and Culturally Diverse Mathematics Classrooms. In Eleventh Congress of the European Society for Research in Mathematics Education; Utrecht University: Utrecht, The Nederland, 2019.

69. Nortvedt, G.A.; Wiese, E. Numeracy and Migrant Students: A Case Study of Secondary Level Mathematics Education in Norway. ZDM Math. Educ. 2020, 52, 527-539. [CrossRef] 